\title{
Climate engineering: a strategic approach to combat environmental potential risks associated with Pak-China Economic corridor (CPEC) Development
}

https://doi.org/10.1515/reveh-2020-0111

Received August 25, 2020; accepted October 3, 2020; published online November 5, 2020

Dear Editor,

\begin{abstract}
China-Pak Economic Corridor (CPEC) has become a future economic potential for both countries. It will serve as a gateway to share trade and other industrial benefits with each other. On one hand it's a blessing for both countries, the other way it is offering a potential threat to the environment i.e. due to wide construction of roads the major effect is threatening biodiversity and environmental sustainability. It will cause deforestation, floods, glacier melting, climate change, and global warming. "Climate engineering" is the newly emerging concept to resolve the problems related to the environment and biodiversity. Under the umbrella of concept "Climate engineering” we proposed attractive and environmentally friendly solutions that are helpful to mitigate the impact of anthropogenic activities on the environment of both countries. These proposed strategies include installation of $\mathrm{CO}_{2}$ scrubbers, construction of Algal ponds, and development of research stations across the roads and by introducing the concept of carbon canopy. It will also help the legislators and policymakers of both countries to incorporate these solutions for sustainable development on each side.
\end{abstract}

Keywords: CPEC; environment; Pakistan.

*Corresponding author: Mahwish Ali, Department of Biological Sciences, National University of Medical Sciences, 46000 Rawalpindi, Pakistan, Phone: +92515124950,

E-mail: mahwishmalik67@gmail.com

Wasim Sajjad, Department of Biological Sciences, National University of Medical Sciences, 46000 Rawalpindi, Pakistan

Abdul Haleem, Department of Microbiology, Quaid-i-Azam University, 45320 Islamabad, Pakistan

Ә Open Access. ( 2020 Mahwish Ali et al., published by De Gruyter. (c))BY International License.

\author{
Scientific and eco-friendly \\ solutions for CPEC-related \\ environmental issues
}

Pakistan is blessed with big reservoirs of glaciers. Karakoram, Himalaya, and Hindukush are among the mightiest mountain ranges in the world, hosts more than 5,000 glaciers in its geographical range. These ranges meet at a junction point in the northern part of Pakistan [1]. The recent advances in science and technology, anthropogenic activities and continuous climate change, glaciers are melting rapidly at an alarming rate resulting glacier retreat events [2]. Moreover, the Pak-China economic corridor (CPEC) project is sanctification for both countries. At the same time, some associated potential threats of CPEC were also highlighted by [3]. These threats include global warming, deforestation, emission of $\mathrm{CO}_{2}$, flooding, agriculture runoff and deterioration of local fauna and flora leads to disturbance of the local biodiversity with the construction of highways. Recent Intergovernmental Panel on Climate Change (IPCC) reported limiting the rise of temperature to $1.5{ }^{\circ} \mathrm{C}$ as compared to the rise of $2{ }^{\circ} \mathrm{C}$ annually for sustainable development [4]. This report also added some SDGs to be followed for environmental sustainability and economic growth with the inclusion of the society [4]. Therefore, there is a practical multidisciplinary approach needed to be called "climate engineering" to cope with all potential threats. This approach incorporates solutions that are cost-effective having less ecological risks, high acceptance in public and are also within the scope of ethical concerns [5]. There are different proposed approaches under the umbrella of climate engineering concept to deal with the above mentioned CPEC associated risks. Two proposed strategies for $\mathrm{CO}_{2}$ (major Greenhouse gas) emission abatement and control include; the installation of $\mathrm{CO}_{2}$ scrubbers and deployment of algal blooms or research stations at different zones that can act as a $\mathrm{CO}_{2}$ scavenger. In this way not only the free $\mathrm{CO}_{2}$ generated will 
be consumed but also it can be an effective source for biofuel production on large scale, which can be utilized by the approximately 7,000 trucks/day that will pass through the CPEC. According to a research report algal biofuels will have about 50 percent lower life cycle greenhouse gas emissions than petroleum-derived fuel [6]. These research stations will also be helpful in globalizing the research; for cost-effective production of not only biofuel but also pharmaceutical ingredients, nutraceuticals and valueadded products derived from algae. Moreover, stopping deforestation in the region of Gilgit Baltistan (covering major glacier zone) is also highly recommended to combat $\mathrm{CO}_{2}$ emissions and glaciers retreat events.

The proposed strategy for agriculture runoff is the construction of wetlands on offside in the CPEC project that will not only helpful in decreasing the eutrophication of freshwater reservoirs by treating the runoff from road and agriculture but also provides the water reuse option to the population sites with no access to freshwater. Furthermore, the installation of the concept of carbon canopy (heavy plantation in the region having high carbon imbalance) is also useful to cope with the emissions of Greenhouse gases (GHG). This plantation will not only be effective in mitigating GHG's emissions but also control soil erosion and flooding in the region. Moreover, implantation of rainwater harvesting conservation and all other strategies will accommodate in decreasing the effect of water famine and food shortage. With all these strategies, there is an esteem need of different research stations to be the part of this CPEC project, that can continuously monitor the emissions of gases to propose and implement solutions on site. Furthermore, the concept of rapid mass transit systems should be incorporated for general public movement and tax should be applied for using the highways. As in 2017,
Government of Pakistan has completed a project of 10 billion tree plantations in the province of Khyber Pakhtunkhwa in response to climate change and global warming. Such type of more actions and all proposed strategies shall be fruitful in cutting off the carbon emission that ultimately limits the rise of temperature and reducing the events of glacier retreat. Moreover, it's the sole duty of the planners and legislators of both countries to make policies and consider these proposed strategies for compliance with environmental sustainability and human health.

\section{References}

1. Rasul G, Chaudhry Q. Z, Mahmood A, Hyder K. W, Dahe Q. Glaciers and glacial lakes under changing climate in Pakistan. Pak J Meterol 2011;8.

2. Kääb A, Berthier E, Nuth C, Gardelle J, Arnaud Y. Contrasting patterns of early twenty-first-century glacier mass change in the Himalayas. Nature 2012;488:495-8.

3. Nabi G, Ullah S, Khan S, Ahmad S, Kumar S. China-Pakistan Economic Corridor (CPEC): melting glaciers-a potential threat to ecosystem and biodiversity. Environ Sci Pollut Control Ser 2018;25: 3209-10.

4. Rogelj J, Shindell D, Jiang K, Fifita S, Forster P, Ginzburget V, et al. Mitigation pathways compatible with $1.5^{\circ} \mathrm{C}$ in the context of sustainable development. In: Global warming of $1.5^{\circ} \mathrm{C}$. Intergovernmental Panel on Climate Change (IPCC);2018: 93-174 pp.

5. DF Cusack, Axsen J, Shwom R, Hartzell-Nichols L, White S, Mackey KRM. An interdisciplinary assessment of climate engineering strategies. Front Ecol Environ 2014;12:280-7.

6. Vasudevan V, Stratton RW, Pearlson MN, Jersey GR, Beyene AG, Weissman JC, et al. Environmental performance of algal biofuel technology options. Environ Sci Technol 2012;46:2451-9. 